\title{
Producción y COMERCio de TABACO EN CentroAméricA A FINES DEL PERÍODO COLONIAL
}

\author{
Production and Trade of Tobacco in Central America by the End of the Colonial Period
}

\author{
Carlos Uriel del Carpio-Penagos
}

Resumen: En este trabajo se analizan las circunstancias del surgimiento de la Real Renta del Tabaco en Guatemala en abril de 1766. El tabaco llegó a representar uno de los rubros más importantes de la economía de la Audiencia de Guatemala, tan sólo por debajo de lo que producían el tributo de los indios y el impuesto de alcabalas, a pesar de que desde la implantación del monopolio real fue sujeto de un fuerte contrabando. También permitió el surgimiento de una extensa, poderosa y corrupta burocracia que cometía abusos principalmente en contra de la población indígena y generaba conflictos con otros funcionarios de la Audiencia.

Palabras clave: Renta del Tabaco, economía, período colonial.

Summary: This paper examines the circumstances of the emergence of the Real income of tobacco in Guatemala in April 1766. Tobacco came to represent one of the most important areas of the economy of the Audiencia of Guatemala just below what produced the tribute from the Indians and Alcabala taxes, while since the implementation of the Royal monopoly was subject of a strong contraband. It also allowed the emergence of a vast, powerful and corrupt bureaucracy that mainly committed abuses against the indigenous population and generated conflicts with other officials in the audience.

Keywords: income from tobacco, economy, colonial period.

Carlos Uriel del Carpio Penagos, doctor en ciencias en ecología y desarrollo sustentable por El Colegio de la Frontera Sur. Investigador titular y docente de la Universidad de Ciencias y Artes de Chiapas y profesor en la Facultad de Arquitectura de la Universidad Autónoma de Chiapas, México. Temas de especialización: formación histórica de las fronteras políticas, manejo de recursos naturales en áreas de fronteras políticas, historia y cultura de Centroamérica. Correo electrónico: carlitosuriel@hotmail.com.
Enviado a dictamen: 29 de agosto de 2013.

Aprobación: 22 de octubre de 2013.

Revisiones: 1 . 


\section{Introducción}

E tabaco (Nicotiana sp) es una planta de la familia de las solanáceas, originaria de América, donde su cultivo y uso estaba ampliamente difundido para fines rituales y medicinales en la época prehispánica, pero cuyo uso para fines sociales y de placer se extendió desde la conquista castellana y portuguesa a Europa y al resto del mundo. ${ }^{1}$

Durante los siglos XVI y XVII, el tabaco que se consumía en España procedía de Cuba y Santo Domingo (Hernández y Teixidor, 1997: 77), y en el resto de las colonias se cultivaba libremente para el comercio local y regional. En Castilla, el incremento del consumo de esta planta fue visto por el Estado como una fuente de ingresos fiscales, por lo que entre los años 1634 y 1636 se estableció el estanco del tabaco, mediante el cual su producción y venta pasó a ser de competencia exclusiva de la Hacienda Real de la Corona de Castilla (Escobedo, 2007: 1027; Hernández y Teixidor, 1997). ${ }^{2}$

En el caso de América, fue a fines del periodo colonial cuando la Corona estableció el control sobre la producción y el comercio del tabaco, en el contexto de las reformas borbónicas. ${ }^{3}$ En Nueva España, la Real Renta del Tabaco se creó el 11 de enero de 1764 bajo la dirección de Jacinto Díez de Espinosa; sin embargo, fue en 1765, con la llegada del visitador Joseph de Gálvez, cuando comenzó a ejecutarse la prohibición del libre cultivo y a controlarse su venta. El visitador Gálvez impulsó también la creación del estanco en Guatemala, donde comenzó a operar oficialmente a partir del 1 de abril de $1766{ }^{4}$

Esta yerba o "fruto", como se referían a ella los funcionarios de la Renta, llegó a constituir el tercer rubro en importancia de la economía de la Audiencia de Guatemala durante la segunda mitad del siglo XVIII, solamente por debajo del tributo de los indios y del impuesto de alcabalas. ${ }^{5}$ En efecto, según un informe del Real Tribunal de Cuentas de la Nueva Guatemala presentado el 28 diciembre de 1777 , el ingreso proveniente de los tributos sumaba 771605 pesos y tres reales, el de Alcabalas 601341 pesos y seis reales y medio, y el de la Renta del Tabaco 347243 pesos y seis reales y medio. ${ }^{6}$
Pese a lo anterior, existen pocos trabajos sobre este tema en la historiografía de la economía colonial de Centroamérica. Entre ellos destaca el de Jorge Luján Muñoz, para el caso de Guatemala, y el de Víctor Hugo Acuña Ortega para Costa Rica. Aunque la Renta del Tabaco se mantuvo después de la Independencia por ser una importante fuente de ingresos fiscales, en este trabajo se analizan datos que abarcan hasta el fin del sistema administrativo de las alcaldías mayores, que en 1790 fue sustituido por el régimen de intendencias.

\section{Establecimiento del estanco del tabaco en Guatemala}

El 20 de febrero de 1765 el rey de España, Carlos III, nombró a Joseph de Gálvez visitador general de los tribunales y casas reales del Reino de Nueva España y consejero honorario de Indias, con la misión de hacer que las rentas de la Corona se incrementaran en ese territorio. Una de las medidas que tomó fue echar a andar el estanco del tabaco que, fundado un año antes, no operaba debido a la oposición del virrey, el marqués de Cruïlles, temeroso de que la medida provocara una reacción popular adversa (Moreno, 2012: 209).

En febrero de 1766, Gálvez subdelegó sus funciones en Sebastián Calvo de la Puerta, oidor de la Audiencia de Guatemala. Lo comisionó para que estableciera la Real Renta del Tabaco en Guatemala y sus provincias, procediendo en todo con acuerdo y aprobación del presidente de la Audiencia, Pedro de Salazar, en cuyo nombre habrían de darse y autorizarse las providencias para que por ese medio se contribuyera al aumento del real erario. ${ }^{7}$

El presidente de la Audiencia elaboró un documento que envió a consultas al Consejo del rey, en el que consideraba que el establecimiento del estanco del tabaco, si bien podía contribuir a sufragar los acrecentados gastos de la Corona al igual que ocurría en México, ${ }^{8}$ también podía ocasionar graves inconvenientes ya que, en caso de presentarse disturbios debido a la prohibición del beneficio, recolección y siembra del "fruto", en Guatemala no se contaba con más de 
treinta hombres que supieran manejar armas. Señala en su misiva que en México fue posible establecerlo "a la sombra de un cuerpo de tropa veterana". A cambio, proponía que para adelantar la Real Hacienda: "sería mejor recaudar de los negros, mulatos y zambos, un correspondiente tributo, atento a que por este medio, no solo se lograría tener noticia de estas gentes sino también incitarlos al trabajo y desterrar la ociosidad a que son dados". 9

Pese a sus recelos y sin esperar contestación a la consulta efectuada, Salazar puso en marcha el proyecto, ya que muy probablemente se dio cuenta, o sus allegados le hicieron ver, que, pese a los vientos adversos barruntados, poner en operación el estanco, del cual Salazar pasó a ser superintendente general, le reportaría grandes beneficios económicos, lo mismo que a una amplia red de aliados y dependientes. La Real Renta del Tabaco inició su actividad con una plantilla de veintiún trabajadores cuyo sueldo en conjunto ascendía a casi dieciséis mil pesos anuales.

Además de los gastos en salarios de los funcionarios, se pagaban 544 pesos anuales de alquiler de una casa, que servía de almacén, oficina de la dirección general y vivienda para el director, lo que implicaba un total de 16336 pesos de gastos fijos.

Don Sebastián Calvo de la Puerta solicitó que entregaran a Francisco de Valdez, Joaquín de Lacunza y Joseph Domingo Salgado, recién nombrados director general, contador y tesorero de la Renta del Tabaco, respectivamente, la cantidad de treinta mil pesos para pagar el tabaco con el que próximamente iniciaría operaciones el estanco, con cargo a la Real Hacienda. A pesar de las protestas de los oficiales reales, que pedían una autorización real, el presidente de la Audiencia decretó el 18 de marzo de 1766 que el dinero les fuera entregado. Los oficiales se negaron tres veces a acceder $y$, aunque finalmente lo hicieron, el 8 de abril de 1766 enviaron una carta al Consejo de Indias en la que informaban del hecho. Así pues, la Real Renta del Tabaco del Reino de Guatemala nació en un contexto de agitación política y de pugnas entre autoridades y funcionarios de la Audiencia y oficiales reales.

\section{Precios, calidades, distritos de cultivo}

Según el decreto de creación de la Renta, el presidente de la Audiencia se debía encargar de su administración y manejo en calidad de superintendente general y juez conservador de ella, "y como tal dará todas las providencias para su más perfecto establecimiento y que se administre como corresponda". ${ }^{10}$ Para dirimir los conflictos que pudieran surgir, se estableció una junta presidida por el superintendente general e integrada por diferentes oficiales de la Audiencia —el decano, dos ministros, el director general y el fiscal-, así como por un inquisidor. ${ }^{11}$

El control que la Renta trató de ejercer sobre el cultivo y comercio de la yerba fue muy estricto. En las garitas de entrada a la ciudad de Guatemala, así como en la Real Aduana, debían registrarse todos los equipajes y carros cubiertos que ingresaran a la ciudad, sin importar a quién pertenecieran. Si los inspectores encontraban tabaco, lo decomisaban e ingresaban a los almacenes de la factoría general, y los infractores eran detenidos.

Para conducirlo desde los pueblos donde se producía hasta la administración o factoría, los dueños del producto tenían que manifestarlo al juez de su territorio a fin de que éste se asegurara de que procedía de los parajes habilitados y, cuando así era, les daba una guía para la administración o factorías donde luego se vendería. A todo el que fuera encontrado sin dichas guías en los caminos se le decomisaba el producto, y al que hubiera denunciado el contrabando se le entregaba una tercera parte del valor del decomiso, otra al juez y la restante a la Renta. ${ }^{12}$

Incluso por el tabaco que alguna persona pretendiera regalar, ésta tenía que pagar un derecho, tal como sucedía con el tabaco de Simojovel y Plátanos que con estos fines se introducía en Ciudad Real, donde se tenía que pagar un derecho de dos reales por cada manojo de ciento treinta a doscientas hojas.

El tamaño de los manojos era muy variable y su regulación fue uno de los problemas principales de la administración de la Renta, hasta que en 1786 se estableció que la unidad de medida para la compra y venta del "fruto" sería el peso del producto, medido en 
onzas y libras; cada manojo de tabaco de cualquier clase debía pesar diecisiete onzas y media, y los cosecheros debían entregarlos bien envueltos en cueros "o liados con sus mismas ojas". ${ }^{13}$

En un inicio se establecieron quince calidades de tabaco en función de su lugar de procedencia y potencia, pero básicamente eran cinco las provincias en las que se producía: Ciudad Real, cuyo tabaco se denominaba Simojovel; Gracias, en el obispado de Comayagua, de donde procedían cuatro variedades del tipo Copán; San Salvador y Chinameca, de donde procedían las variedades Istepeque y Chinameca; Estelí, en el obispado de León, donde se cultivaban los denominados Estelíy Valle del Molino; y por último Costa Rica, donde se cultivaba, a decir de los documentos de la época, un tabaco bastante malo cuyo consumo se restringía a la ciudad de Granada y sus alrededores.

Se establecieron fielatos - lugares donde se recibía y pesaba el producto - en la Antigua Guatemala, donde se encontraba también la dirección general, en Totonicapán, San Antonio Suchitepequez, Quetzaltenango, Sonsonate, Verapaz, Escuintla/ Guazacapan, Soconusco, Tegucigalpa, Matagalpa, Costa Rica y Comayagua. También se establecieron una tercena - almacén donde se vendía al por mayoren la Antigua Guatemala; tiendas que vendían al por menor o estanquillos en esta misma ciudad, en el pueblo indígena de Patzicia y en Petapa; y administraciones en Sololá, Chiquimula, León, San Salvador, Granada y Ciudad Real. En esta última provincia, su alcalde mayor, Fernando Gómez de Andrade, proporcionó los 366 pesos y seis reales que costó establecer la oficina receptora. ${ }^{14}$

En la mayoría de los pueblos y provincias donde se establecieron dependencias del estanco, el encargado era el alcalde mayor de la provincia, el corregidor o, como en el caso de Patzicía, su gobernador indígena. Los tercenistas entraban al negocio con la expectativa de ganar el 4\% sobre las ventas. La administración proporcionaba el dinero para que se efectuaran las compras a los cosecheros y para que se los habilitara para el cultivo. ${ }^{15}$

En el mapa 1 se muestra la distribución de las áreas de producción, señaladas con un cuadrado con puntos dentro de su perímetro, y las localidades, señaladas con un cuadrado dividido en cuatro cuadrantes.

\section{Contrabando}

En provincias como Gracias del obispado de Comayagua, donde el cultivo y comercio de esta planta era muy abundante y se llevaba a cabo mediante operarios asalariados, las tarifas de compra y venta y las calidades impuestas por el estanco ocasionaron protestas de los cosecheros, quienes provocaron la escasez del producto dejando de sembrarlo, además de que se dedicaron a contrabandearlo. En abril de 1769, Domingo Claros, Joseph de Heraso, Thomas de Tabura, Jacinto Dubon, Nicolas de Lara y Manuel de Carabantes, vecinos de la ciudad de Gracias a Dios, elevaron una "representación" a la junta, máximo órgano de gobierno de la Renta del Tabaco, en la que se quejaban por las tarifas de compra, "con precios tan ínfimos que nos fue de notable perjuicio y deterioro en nuestros haveres y comercio", además de por las calidades establecidas por el estanco:

Tan extraño a nuestro conocimiento porque cuando en el discurso de tantos años que labramos este efecto haviendonos criado entendiendo en su facultad, solo le conocemos por dos calidades que son, la primera de fuerte, y la otra de suave [regularmente nombrado manjua], sin atención a que sea largo o corto, pues solo mirábamos su fortaleza o suavidad. ${ }^{16}$

Además del precio de compra y venta y de las calidades, el estanco, a través de la factoría general, determinó el tamaño de los bultos, de modo que los manojos debían contener ochenta hojas, los tercios ochenta manojos y las cargas ciento sesenta manojos - es decir, dos tercios hacían una carga- Antes del establecimiento del estanco, los cosecheros de Gracias llevaban su tabaco de segunda calidad, es decir, el suave o manjua, a la ciudad de Guatemala y dejaban almacenado en sus casas el de primera calidad, con cuya venta posterior se resarcían de las posibles pérdidas ya que, aun al precio de un real o real y medio el manojo, los compradores de otras provincias acudían a surtirse de él, de modo 
que los cosecheros ahorraban el costo de traslado. Sin embargo, si lo tenían que sacar por su cuenta, el precio que alcanzaba era de cuarenta pesos por carga, lo que representaba para ellos un costo considerable. Ante el control establecido por el estanco, los cosecheros de Gracias optaron por el contrabando, tal como lo indica el administrador del fielato de Tegucigalpa, Joseph Gonzalez Agüero, en una carta al director general de la Renta de junio de 1769. En su misiva se quejaba de la poca cantidad que habían entregado los cosecheros en los almacenes reales y de que en los estanquillos de la provincia no se vendía la existencia, lo que, según su juicio, "manifiesta el extravío que han hecho del género". También el tesorero de Sonsonate se quejaba de lo mismo y solicitó guardas y ministros para que fomentaran la siembra y evitaran el contrabando.

En Ciudad Real también floreció el contrabando durante los dos primeros años de la Renta, pero en 1768 se nombró a un administrador y a un guarda, con seiscientos y trescientos pesos anuales de sueldo. Este último asistió a la cosecha al pie de las milpas, de modo que pasó la recaudación de 7500 manojos a 20 0.17

Las disposiciones iniciales para el funcionamiento del estanco fomentaron el contrabando ya que, de una situación previa en la que el cultivo y el comercio del tabaco eran libres, trató de pasarse a una situación de total control, sin que las medidas impuestas se acompañaran del personal suficiente para hacerlas cumplir. Por otra parte, los dos primeros años fueron caóticos debido a que en la práctica existían dos directores, Sebastián Calvo de la Puerta y Francisco de Valdés, quienes a menudo emitían órdenes contradictorias, además de que la contaduría se llevaba sin orden ni método, según informa en 1772 el nuevo director Tiburcio Ángel de Toledo. ${ }^{18}$ Esta situación la aprovechaban las administraciones subalternas para no rendir cuentas claras de sus actividades. Desde su llegada a la dirección general en 1768, Toledo inició una transformación profunda y agresiva de la Renta del Tabaco que consistió en:

1. incrementarelpersonal para evitar el contrabando,

2. impedir la siembra en Thegucigalpa, Comayagua,
San Salvador "y las muchas siembras clandestinas que hay en diversos parajes de estas provincias",

3. ceñir el cultivo exclusivamente a Costa Rica para el abasto de la Provincia de Nicaragua "porque sus moradores no gustan otro". A Gracias y Valle de Copán, para la provincia de Comayagua, Thegucigalpa, San Salvadoryla Antigua Guatemala, donde debía venderse también el que se producía en el Valle de Molino — actual Nicaragua - y a Simojovel para el suministro de la provincia de Chiapa, Soconusco, San Antonio, Quetzaltenango, Totonicapán y Sololá y el sobrante para la antigua Guatemala.

Según Toledo, la provincia de Gracias a Dios, en el Valle de Copán, sería capaz por sí sola de abastecer todo el reino si tuviera gentes que cultivaran el tabaco. Para lograr esto, propuso que se le suministrara mano de obra de las provincias de Comayagua y Chiquimula, por lo que trajo de ellas cuantos indios fueron necesarios, además de poner funcionarios encargados de la siembra y aumentar el precio del producto para que alcanzara a sufragar los gastos de la administración y dejar utilidades al rey.

Toledo también cambió las tarifas vigentes hasta entonces. Aumentó de un 20\% a un 25\% el precio de compra de todas las variedades de Copán, lo que incrementó considerablemente el precio de venta al público a pesar de que los precios vigentes en ese momento dejaban ganancias significativas. En la variedad de Copán largo se ganaba una utilidad del $100 \%$ al 150\%, y en la de Copán corto del 175\%. En el tabaco procedente del Valle del Molino se obtenía una utilidad aún mayor que en el de Copán, pese a que su calidad era inferior. El de Simojovel, a pesar de los elevados costos de traslado hasta los almacenes donde se expendía, rendía un $100 \%$ de utilidades, mientras que el Costa Rica dejaba en Granada algo más del $200 \%$ de utilidad.

Aumentaron el precio de las variedades de mayor demanda hasta el 100\%, medida que justificaban con el argumento de que aquel que quisiera mantener "el vicio de fumar... lo pague a más subido precio". 
Según juicio del nuevo director, los administradores eran quienes fomentaban el contrabando y las siembras clandestinas, por lo que propuso que se crearan los puestos de visitadores, con un salario anual de mil pesos, quienes estarían sujetos exclusivamente a su autoridad. Estos funcionarios debían acompañar a los guardas y visitar todas las administraciones y fielatos del territorio, donde deberían registrar los almacenes y los libros de cuentas para descubrir los fraudes que cometían los funcionarios y disuadir de siembras clandestinas. El trabajo que estos funcionarios tenían que realizar era extenuante debido a la amplitud del territorio a vigilar; por ejemplo, había un visitador para atender los partidos de Chimaltenango, Sololá, Totonicapán, Quetzaltenango, San Antonio, Soconusco, Chiapa, Verapaz y Escuintla; y otro debía recorrer Petapa, Chiquimula, San Salvador, Realejo, Granada, Matagalpa, Tegucigalpa y Comayagua.

Tiburcio Ángel de Toledo solicitó al presidente de la Audiencia que se quitara de la administración de la Renta en las diferentes provincias del reino a los gobernadores, alcaldes mayores y corregidores, quienes consideraban que su autoridad superior era solamente la Real Audiencia y no el director de la Renta del Tabaco, por lo que no obedecían las órdenes de éste o lo hacían con lentitud y fricciones; propuso sustituirlos por particulares. Toledo mencionaba en una carta fechada el 3 de abril de 1771:

[...] el Director se ve muchas veces precisado a disimular lo que no debiera tolerar y a estudiar los términos con que escribirles por no exponerse a que le falten al decoro que le corresponde por su empleo, los particulares por el contrario estarían sujetos al Director, quien podrá escribirles con sequedad quando lo pidan las circunstancias de los acontecimientos sin recelo de que le respondan con

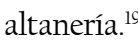

En la Provincia y Administración de San Salvador puso un guarda mayor con un salario de cuatrocientos pesos anuales, y seis guardas con trescientos pesos anuales de salario cada uno; lo mismo hizo en Granada y en Sonsonate. En las provincias de Comayagua y Tegucigalpa, mientras tuvieran siembras, en cada una intervendría un guarda mayor con un salario de cuatrocientos pesos, y cuatro guardas con salarios de trescientos pesos. En Gracias a Dios, donde más tabaco se cosechaba, instaló un guarda mayor y dos guardas; el primero con trescientos pesos de sueldo y los otros con doscientos cincuenta. En Chiquimula puso un guarda y otro en Zacapa, con doscientos cincuenta pesos de salario cada uno, así como uno en Verapaz, dos en la provincia de San Antonio y dos en Quetzaltenango, con un sueldo de trescientos pesos cada uno.

Toda esta reorganización implicó un costo en salarios anuales de 16850 pesos, y el director tuvo el cuidado de señalar que era necesario pagarles porque de lo contrario "serán los mayores defraudadores de la Renta [...] parece una cifra exorbitante”. Decía el director:

[...] pero si se considera que su sola presencia hara que todo el tabaco que se coge venga a los reales Almacenes y que únicamente el rey sea quien lo venda, se percibirá lo que crecerá la renta y aumentándose con los sobreprecios señalados será tan bentajosa la utilidad que pueda mantenerlos y dejar a su Magestad mayores adelantos, sin comparación con los que hoy logra [énfasis del autor]. ${ }^{20}$

También recomendaba que se promulgaran bandos en los que se prohibiera a cualquier persona, sea de la calidad que fuere, comerciar tabaco en rama, polvo o desmenuzado, "aunque sea el que hayan comprado en los Reales estanquillos, porque esto ha de ser pribatibo al Rey, dejándoles el privilegio que no gozan en otras partes, de fabricar puros y cigarros". ${ }^{21}$

\section{Ciudad Real: de fielato a factoría}

Inicialmente, en Ciudad Real se estableció un fielato, que era un puesto de acopio de menor importancia que una administración o una factoría, a cargo del alcalde mayor, Fernando Gómez de Andrade, quien, como se mencionó antes, financió el establecimiento del fielato poniendo de su bolsillo 366 pesos para la compra de 
utensilios y muebles. En la instrucción 54 del decreto de creación del estanco se estableció que el fielato de Ciudad Real se surtiera de Simojovel y Plátanos, y que dicho tabaco se debería consumir "en aquella jurisdicción cuidando su administrador que no salga de ella, para las de Quesaltenango, Totonicapán ni otros pueblos del Arzobispado de Guatemala, a menos que se pida por el Director en alguna urgencia”. ${ }^{22}$ Esta disposición permitió que dicho tabaco no contara con un precio oficial de compra y venta, por lo que la tarifa quedó a consideración de Gómez de Andrade, quien se distinguió por defraudar a la Renta durante el tiempo en que Francisco de Valdés fue director general.

En el primer año de operación de la Renta, su contador general, Joaquín Lacunza, reportó tener en almacén 901 manojos de tabaco de Simojovel, los cuales se vendían en ese año a real y medio el manojo, por lo que sumaba su importe un total de 168 pesos, 7 reales y 17 maravedíes. Además, tenía 38 manojos "de otro de Simojovel a uno y quartillo reales", lo cual sumaba 5 pesos, 7 reales y 17 maravedíes; 107 manojos más “de otro de Simojovel a real", lo cual sumaba la cantidad de 13 pesos y 3 reales. ${ }^{23}$ Es decir, durante el primer año de operación de la Renta el valor total del tabaco proveniente de Simojovel y Plátanos fue de 186 pesos, 17 reales y 34 maravedíes.

Comparado con el partido de Gracias, donde se producía el tabaco de Copán, lo producido en Simojovel y Plátanos era mínimo. Para 1767, año en que se reportaron las existencias del primer año de operaciones del estanco, había 44691 manojos de "Copán largo fuerte" a razón de 16 pesos cada carga de 160 manojos, lo que representaba un total de 4469 pesos y 27 maravedíes; había también 21467 manojos de "Copán largo suave", a 10 pesos cada carga de 160 manojos, que sumaban un total de 1342 pesos, 2 reales y 17 maravedíes. Del "Copán corto fuerte", se reportó una existencia en almacén de 10151 manojos, que a un precio de "treze pesos carga de siento y sesenta manojos" produciría un total de 824 pesos, 6 reales y 5 maravedíes, mientras que del "corto y suave", se tenían 4765 manojos, que, vendidos a 8 pesos cada carga de 160 manojos, producirían 238 pesos y 2 reales. ${ }^{24}$
Al contrario de lo que sucedía en Gracias, donde el cultivo de tabaco corría a cargo de españoles radicados en las cabeceras de provincia o incluso en la capital de la Audiencia, en Chiapas la mayor parte de la población involucrada en el cultivo de tabaco era gente pobre e indígena, sometida a todo tipo de abusos. ${ }^{25}$ Como ya se indicó, en la provincia de Ciudad Real el tabaco se cultivaba casi con exclusividad en el partido de La Guardianía, principalmente en Simojovel, Huitiupán, Plátanos y San Pedro -Chenaló-, pueblos cuya población era en su totalidad de origen indígena, excepto por algunos funcionarios reales y eclesiásticos. El territorio de La Guardianía tenía en 1778 una población compuesta por 6 españoles, 11 negros y mulatos, y 2955 indios y naboríos, según el censo levantado por el obispo Francisco Polanco (De Vos, 2010: 106). ${ }^{26}$

En octubre de 1768, el nuevo director, Tiburcio Ángel de Toledo determinó fijar un precio oficial de los tabacos de Simojovel y Plátanos e introducirlos para su venta en las tercenas de la capital de la Audiencia. ${ }^{27}$ Para esto nombró una comisión de "reconocedores" integrada por José Joaquín de Valenzuela, Alonso Gutiérrez, Manuel de la Bárcena y Muñoz y Toribio Balverde, quienes, con base en su experiencia de tercenistas, determinarían la calidad de los mismos, así como el precio al que convendría comprarlos y venderlos, por comparación con la calidad y precios de los demás tabacos del reino. Todos ellos, al preguntárseles si conocían la calidad, naturaleza y bondad de los tabacos de Simojovel y Plátanos, así como el número de hojas que componían un manojo y el precio al que podrían venderse, respondieron que este tabaco tenía mayor similitud con el de Copán y que, en tiempos anteriores al establecimiento del estanco, un manojo de estos tabacos contenía entre 180 y 200 hojas, por lo que podía valer de seis a siete reales el manojo.

Sin embargo, dado que no todos los consumidores disponían de esa cantidad para la compra de un manojo entero, el licenciado Zelaya, asesor de la Renta, recomendó que se midieran los manojos de manera tal que pudieran venderse de real en real o de dos en dos reales, según fuera más conveniente. No obstante, al ejecutarse esta recomendación se dieron cuenta de que 
no todos los manojos tenían, como se había informado, doscientas hojas, sino que muy pocos manojos llegaban a ese número, y lo regular era que tuvieran de 180 hojas para abajo, hasta 130:

[...] y siendo este punto imposible de asegurarse al tiempo del recibo de los tabacos en la Dirección porque para esto era preciso deshacer los manojos y contar las hojas, cuya operación seria demasiadamente prolija y costosa y también perjudicial porque se disiparían los espíritus del tabaco, desmereciendo su estimación [se indicó] que para compensar las faltas de unos manojos con las sobras de otros, y al tiempo de dividirlos en reales para la venta, no padezca quebranto el Real erario, se forme de veinte y cinco ojas cada manojo que se ha de vender a real y a los mismos seis reales en que se regula el manojo entero según sale de mano del cosechero. ${ }^{28}$

Otro cambio importante se dio a partir del 19 de diciembre de 1768, cuando el presidente de la Audiencia nombró como administrador de Ciudad Real a Esteban Gutiérrez de la Torre, con un salario de seiscientos pesos, así como un guardia "amovible" al arbitrio del administrador, con trescientos pesos anuales de sueldo. Nombró también seis estanqueros en Ciudad Real, Tuxtla, Comitán, San Bartolomé — de los Llanos-y Tecpatán, ${ }^{29}$ a los que asignó cincuenta pesos al año, y, a otro de Ixtacomitán, setenta y cinco. Esta decisión elevó el fielato al rango de administración. ${ }^{30}$

En 1772, los cambios introducidos permitieron al administrador contabilizar que, aún pagando el salario de un guarda mayor, ocho guardas, un ministro y un escribiente, que percibirían entre todos 1135 pesos de salario anual, el rey obtendría una utilidad de 2089 pesos. Sin embargo, a pesar de estas sensibles mejoras y del aumento del personal, el contrabando persistía, como se deduce de la publicación de un bando promulgado por el gobernador intendente de la provincia, Franco Saavedra Carvajal, en junio de 1787, en el que señala que todo aquel que se atreviera a sembrar tabaco fuera del distrito de Simojovel, sin el permiso del estanco y sin importar quien fuera, perdería las tierras donde se hallaran las siembras y purgaría una pena de seis años de prisión. Si el infractor fuere comerciante, perdería las caballerías o carruajes además de quedar preso. El bando también ordenaba que todos los subalternos del intendente debían recorrer el territorio y destruir los plantíos que encontraran, aún los de tabacos cimarrones o silvestres. Los negligentes serían acusados de fraude y encubrimiento, perderían sus empleos y se harían merecedores de castigos de prisión más rigurosos que los que recibiría el mismo defraudador aprehendido. Sobre los cosecheros autorizados, éstos debían entregar al comisario del partido todo el tabaco que cosecharan sin extraer ninguna porción aunque fuera ésta para su consumo; si no lo hicieren, serían castigados con cincuenta azotes la primera vez, cantidad que aumentaría en caso de reincidencia.

A estas medidas normativas, en el curso de esos años se incrementó el personal de la ya para entonces Factoría de Ciudad Real. Entre el nuevo personal sobresalían los guardas volantes y los guardas de los pasos o caminos obligados, como el guarda de Bochil, apostado en ese lugar para controlar la salida hacia los valles centrales, y el guarda del paso de La Canoa, en el río Grijalva, ruta obligada para ir de Ciudad Real a Tuxtla y al Istmo de Tehuantepec. En 1791 se consideraba que el tabaco de Simojovel era de los que más utilidad dejaba a la Renta, y el lugar donde se cosechaba era considerado como propicio para surtir a muy bajo costo el extremo noroccidental de la Audiencia.

En ese año el factor era don Luis Martínez Trujillo, quien recibía un sueldo de mil doscientos pesos anuales. Era auxiliado en sus funciones por un contador, don Joseph Aguilar, que recibía un salario de seiscientos pesos anuales; un fiel de almacenes, don Pedro Corona, con trescientos pesos anuales; un guarda del casco, Domingo Camacho, con un sueldo de doscientos pesos anuales; dos visitadores, Josef Francisco Gutiérrez y Josef Córdova, con cuatrocientos pesos cada uno; tres guardas volantes, con trescientos pesos anuales cada uno; un comisario de siembras, Rafael Tovar, con cuatrocientos pesos; dos guardas de siembras, ${ }^{31}$ uno, Josef Castro, con ciento cincuenta, y otro, 
Andrés Hernández, con cien pesos; un comandante del resguardo, Antonio Alonso Fernández, con cuatrocientos pesos; Juan Zenteno, como guarda en el paso del Vochil [sic], con cien pesos; Josef Muñoz, como guarda en el paso de La Canoa de Chiapa, con doscientos pesos, y un mozo de almacenes con ciento veinte pesos. Los salarios de este personal ascendían a 5770 pesos anuales. ${ }^{32}$

Con el crecimiento de la importancia del estanco del tabaco y los cambios administrativos registrados se generaron conflictos de autoridad con los alcaldes mayores, corregidores y gobernadores indígenas, quienes, sin duda, más se beneficiaban de la compra y venta del producto, así como del contrabando y las siembras clandestinas. La creación de un cuerpo de milicia dependiente de la Renta socavó la autoridad de los alcaldes mayores, que hasta entonces controlaban las fuerzas del orden en sus provincias, por lo que la presencia de una policía para el resguardo del estanco disminuía su autoridad e importancia, además de poner fin a su impunidad. Sin embargo, la persistencia del contrabando es un indicio de que muchas autoridades estaban implicadas y lo favorecían. Todos los directores tomaron en su momento las medidas que consideraban necesarias para acabar con "los insectos nacionales que roen y consumen" [las utilidades]. ${ }^{33}$

\section{Conclusión}

La producción y comercio de tabaco era un ramo de la economía colonial de Centroamérica muy importante tanto para la Hacienda Real y sus funcionarios, como para los dependientes del gobierno de la Audiencia y algunos allegados. El estanco proporcionaba ganancias a la mayoría de los involucrados en la producción y el comercio de tabaco. La Corona obtenía considerables ganancias, los funcionarios de la Renta y la Audiencia hacían negocios utilizando el dinero de la Hacienda Real, además de disfrutar de un salario permanente y de prerrogativas especiales. También se vieron favorecidos algunos cosecheros españoles que establecieron plantaciones en las áreas de mayor productividad, como el Valle de Copán en la provincia de Gracias a Dios, obispado de Comayagua, y que llevaban a cabo la actividad mediante la fuerza de trabajo de indios que les eran entregados en repartimiento por las autoridades.

Sin embargo, en el caso de la Intendencia de Ciudad Real, un territorio de frontera muy alejado del centro político de la Audiencia y con una numerosa población indígena, la producción recaía en pequeños campesinos y comuneros de los pueblos de indios de Simojovel y Huitiupán principalmente, a quienes se les fijaba cuotas de producción y se les castigaba severamente si no cumplían con ellas, además de que se les obligaba a conducir la cosecha hasta los almacenes del estanco en Ciudad Real por su propia cuenta. Aquellos otros que no formaban parte de los pueblos autorizados para la siembra, como Zinacantán y Chamula, debían prestar su fuerza y sus recursos para trasladar las cargas de tabaco a Quetzaltenango, en un viaje de varias semanas en el que con frecuencia morían extenuados por el esfuerzo.

El funcionamiento del estanco del tabaco también generó conflictos entre los diferentes ámbitos de la burocracia, ya que los funcionarios de la Intendencia, como alcaldes mayores y gobernadores de los pueblos de indios, vieron amenazados su poder y privilegios por los nuevos funcionarios reales, que eran la punta de lanza de las reformas borbónicas en los pueblos y que tenían la misión tácita de arrebatarles el control de los mismos en beneficio del poder central. Estos conflictos de poder entre burócratas, aunados al descontento generalizado entre las poblaciones locales por los abusos cometidos por los funcionarios reales con el pretexto de incrementar las utilidades del estanco, alimentaron el descontento que se precipitó a partir de 1810 y que condujo a la Independencia de Centroamérica.

El estudio del estanco del tabaco es un campo de investigación de la historia económica de la región, y de Chiapas en particular, durante el período colonial, que inexplicablemente se ha trabajado muy poco pese a la abundante documentación existente y a su innegable importancia para comprender diversos aspectos del devenir de estos pueblos. 


\section{Notas}

${ }^{1}$ La consulta de documentos en el Archivo General de Indias en Sevilla, y en el Archivo el de Centroamérica en la ciudad de Guatemala, fue posible gracias al apoyo de PROMEP mediante el financiamiento del proyecto de la red de investigación "Tradición y modernidad en tres regiones de México", desarrollado conjuntamente entre los cuerpos académicos "Estudios regionales" del Centro de Estudios Históricos y Ciencias Sociales de la Universidad de Guadalajara, "Historia" de la Facultad de Filosofía de la Universidad Autónoma de Querétaro, y "Patrimonio sociocultural" del Centro de Estudios de México y Centroamérica de la Universidad de Ciencias y Artes de Chiapas.

${ }^{2}$ Excepto entre 1684 y 1687, años en los que la Renta estuvo directamente administrada por la Corona por no hallarse arrendatario satisfactorio, desde su creación hasta 1701 la Renta del Tabaco, como otros ramos hacendarios, se concesionaba a un particular, quien pagaba por adelantado la cantidad de dinero que la Corona estipulara y se hacía cargo del cobro de los tributos o, como en el caso del tabaco, recibía el monopolio de su elaboración y comercio (Escobedo, 2007: 1027).

${ }^{3}$ Lasreformas borbónicas fueron los cambiosintroducidos por los monarcas borbones Felipe V, Fernando VI y especialmente Carlos III, durante el siglo XVIII, en aspectos económicos, políticos y administrativos, tanto en el territorio peninsular de la Corona como en sus posesiones ultramarinas de América y Filipinas. Entre 1760 y 1808 se implantaron cambios en materia fiscal, en la producción de bienes, en el ámbito del comercio $\mathrm{y}$ en cuestiones militares. Estos cambios condujeron al aumento de la recaudación impositiva, así como a reducir el poder de las élites locales y a aumentar el control directo del poder central sobre la vida económica de las colonias.

${ }^{4}$ Los últimos territorios españoles en América donde se estableció el monopolio real del tabaco fueron Venezuela en 1777, Guayaquil en 1778 y Paraguay en 1779.

${ }^{5}$ En el caso de Nueva España constituyó el segundo rubro de la economía, tan sólo por debajo de la minería (Moreno, 2011: 207).
${ }^{6}$ El 15 de noviembre de 1730, Felipe V estableció la Real Junta de Moneda, iniciativa que dio origen al sistema monetario español y que unificó el tipo de moneda y sus equivalencias en todos los territorios españoles. Se crearon monedas de oro y de plata; el llamado "real de a ocho" se denominaba "peso fuerte", "peso duro" o simplemente "peso", y se componía de ocho reales, cada uno de los cuales se dividía a su vez en 34 maravedíes. El real de a ocho fue una moneda que se usó en grandes cantidades para el comercio español tanto en América como en Asia, por lo que se convirtió en la primera divisa de uso mundial. Un real de a ocho tenía un peso nominal de 27468 gramos, con una pureza de 0.93055\%, es decir, contenía 25560 gramos de plata. En 1771, Carlos III ordenó bajar la ley de las monedas, tanto de oro como de plata, por lo que el real de a ocho pasó a tener veinte gramos de plata. A partir del 5 de enero de 1783 empezaron a emitirse billetes de banco, que serían admitidos como dinero efectivo en todas las tesorerías y se darían en todos los pagos sin excepción alguna. Circularían al portador y serían transferibles sin necesidad de endoso. Tendrían curso obligatorio dado que se podía acudir al Banco de San Carlos en cualquier momento para cambiarlos por dinero en metálico. Se emitieron billetes con denominaciones de 200, 300, 400, 500, 600, 700, 800, 900 y 1000 reales. La primera emisión lanzó billetes por valor de 52 millones de reales, y para soportar dicha emisión la Real Hacienda depositó en el Banco treinta millones de reales en oro. Para una explicación más detallada del sistema monetario de la época pueden consultarse Ruiz Trapero $(2004,2007)$ y De Santiago (2007).

${ }^{7}$ Archivo General de Indias, Guatemala, 775. Después de 2006, el Archivo General de Indias cambió su sistema de clasificación. Dejó de existir el anterior que incluía el número de expediente y el legajo, y quedó solamente vigente la signatura, que sirve para agrupar documentos por países, años y temas.

${ }^{8}$ Se conserva el nombre con que se refieren a la Nueva España en el documento referido.

${ }^{9}$ Archivo General de Indias, Guatemala, 775.

${ }^{10}$ Archivo General de Indias, Guatemala, 775.

${ }^{11}$ Archivo General de Indias, Guatemala, 775. 
${ }^{12}$ Ninguna persona estaba exenta de ser procesada, ni siquiera los eclesiásticos. Templos y monasterios podían ser cateados "siempre que se tuviera justificación o fundada sospecha de ocultarse el contrabando en los lugares sagrados". Lo mismo ocurría con los caballeros de las órdenes militares, a quienes se les decomisaba el producto, aunque para las penas a imponérseles el superintendente general debía consultar al rey, quien era el gran maestre de las órdenes militares - Santiago, Calatrava y Alcántara-, las cuales eran un instrumento de preservación de la nobleza y de la discriminación social (Escobedo, 2009: 278).

${ }^{13}$ Archivo General de Indias, Guatemala, 778.

${ }^{14}$ Archivo General de Indias, Guatemala, 775.

${ }^{15}$ La habilitación de los cosecheros era una práctica habitual que desde antes del establecimiento de la renta se hacía, sobre todo considerando que los agricultores eran extremadamente pobres. En Paraguay, por ejemplo, antes de que la Renta del Tabaco se fundara, los mercaderes suministraban a los cosecheros de tabaco carne, mulas, lienzos de algodón, herramientas, medicinas y otros insumos. Eventualmente, también tomaban a su cargo el pago de jornales, de transporte y de fletes.

${ }^{16}$ Archivo General de Indias, Guatemala, 775 (año 1772, número 6, testimonio de la Ynstancia de los Labradores de Tabaco del partido de Gracias a Dios, sobre aumento de precios...).

${ }^{17}$ Archivo General de Indias, Guatemala, 775 (año 1772, número 6, testimonio de la Ynstancia de los Labradores de Tabaco del partido de Gracias a Dios, sobre aumento de precios...).

${ }^{18}$ Tiburcio Ángel de Toledo se hizo cargo de la dirección general de la Renta del Tabaco el 1 de noviembre de 1768 a raíz de los graves achaques por enfermedad de Francisco Valdés. Entró al servicio burocrático en 1761, como alcalde mayor de los partidos de Totonicapán y Huehuetenango: "importaban sus tributos diez mil quatrocientos setenta y cinco pesos un real al año" y en 1766, cuando dejó de ser alcalde mayor, "montaban sus tributos al año once mil quatrocientos veinte y cinco pesos y seis reales". El aumento de la recaudación se debió a que a su llegada formó un nuevo padrón para incrementar la base tributaria.
${ }^{19}$ Archivo General de Indias, Guatemala, 775.

${ }^{20}$ Archivo General de Indias, Guatemala, 775.

${ }^{21}$ En Centroamérica, el estanco del tabaco no evolucionó hacia la industrialización del producto, como en el caso de Nueva España, donde desde los primeros años se estableció una fábrica de puros y cigarros en Córdoba, Veracruz. En Centroamérica el comercio se efectuaba en rama y desmenuzado para el consumo personal, y se dejó a los hombres y mujeres más pobres de las áreas urbanas la opción de ganarse la vida elaborando y vendiendo al detalle puros y cigarrillos con tabaco que debían comprar al monopolio real.

${ }^{22}$ Archivo General de Indias, Guatemala, 775.

${ }^{23}$ Archivo General de Indias, Guatemala, 775.

${ }^{24}$ Archivo General de Indias, Guatemala, 775.

${ }^{25}$ Pero los abusos no eran privativos de Chiapas y el Soconusco; en abril de 1770, Pedro de Salazar, presidente de la Audiencia, avisó al Consejo de Indias de que tomaría medidas contra el administrador del estanco en Nicaragua, donde "el factor don Joseph Antonio Guerrero, que reside en Granada y don Francisco Esteban Sanchez de Utrera, que cuida de la terzena en la capital de la provincia" cometieron "actos vejatorios a los cosecheros y al público," aunque no especificaba en qué consistieron éstos.

${ }^{26}$ Aunque está fuera del periodo analizado en este artículo, en una lista de cuarenta y cinco cosecheros de Simojovel, del año 1811 aparecen cuatro de ellos con el apelativo de "Don" antes de su nombre, por lo que es probable que sean los únicos españoles, además del comisario de siembras, que también tenía una milpa con 10599 plantas. Los cuarenta restantes aparecen enlistados por sus nombres, pero sin ser llamados "Don", y además tienen apellidos indígenas indiscutibles, como Ayosil, Tzunun, Matz, Oquil, Tulán, Bachajón, entre otros (Archivo General de Centroamérica, A3.13 (1), exp. 03753, leg. 67, Estado de las sementeras de tabaco en el pueblo de Simojovel, abril 16 de 1811).

${ }^{27}$ El traslado de la capital de la Audiencia a la hoy ciudad de Guatemala se produjo en 1775 a raíz del terremoto que en julio de 1773 destruyó la mayor parte de la ciudad de Santiago de los Caballeros o Antigua, donde originalmente se encontraban la dirección general y los 
almacenes de la Renta del Tabaco. A mediados del siglo XVIII, Antigua tenía una población de 33000 habitantes, pero en octubre de 1773, a tres meses del terremoto, su población había disminuido a 1532 familias, que hacían un total de 9203 vecinos (Johnston, 2005: 6).

${ }^{28}$ Archivo General de Indias, Guatemala, 778.

${ }^{29}$ En 1785, Tecpatán, Comitán, Tuxtla e Ixtacomitán tenían rango de factoría y en Ocosingo se había abierto una tercena, lo mismo que en Chilum, Chilón y Huitiupán. En 1789 se abrió una tercena en Yajalón y una factoría en Palenque.

${ }^{30}$ Archivo General de Indias, Guatemala, 776.

${ }^{31}$ Los guardas tenían, además del salario, la prerrogativa de quedarse con una tercera parte de lo que incautaran en sus visitas.

${ }^{32}$ Archivo General de Indias, Guatemala, 780.

${ }^{33}$ El tabaco era una fuente importante de recursos para la población local. Con ellos pagaban al alcalde mayor las mercancías que les obligaban a comprar mediante el repartimiento, además de que servían de apoyo para que los campesinos pudieran producir maíz, gallinas, mantas, chile y otros productos que entregaban al alcalde mayor como tributo en especie o vendían para pagar su tributo en dinero (Archivo General de Centroamérica, A3.13 (1), exp. 03328, leg. 1798).

\section{Referencias bibliográficas}

Acuña Ortega, Víctor Hugo, (1974) Historia económica del tabaco en Costa Rica: época colonial. Tesis de licenciatura. Costa Rica, Universidad de Costa Rica.

Amores Carredan, Juan Bosco, (1999) "La renta del tabaco en Cuba a finales del s. XVIII", en González Enciso, Agustín y Rafael Torres Sánchez (eds.), Tabaco y economía en el siglo XVIII. Pamplona, Ediciones Universidad de Navarra. Disponible en: www.ehu. es/bosco.amores/publicaciones/026_renta_tabaco Cuba_fines_XVIII.pdf [consultado el 8 de febrero de 2013]

De Santiago Fernández, Javier, (2007) "Legislación y reforma monetaria en la España borbónica”, en Galende Díaz, Juan Carlos y Javier de Santiago Fernández (eds.), VI Jornadas Científicas sobre Documentación
Borbónica en España y América (1700-1868). Madrid, Departamento de Ciencias y Técnicas Historiográficas de la Universidad Complutense de Madrid. Disponible en: http://pendientedemigracion.ucm.es/centros/cont/ descargas/documentoll398.pdf [consultado el 17 de octubre de 2013]

De Vos, Jan, (2010) Vienen de lejos los torrentes, Una historia de Chiapas. Tuxtla Gutiérrez, Consejo Estatal para la Cultura y las Artes de Chiapas.

Escobedo Romero, Rafael, (2007) "Los empleados de la renta del tabaco durante los siglos XVII y XVIII: el imán del privilegio" en Hispania, Revista Española de Historia. Vol. LXVII, núm. 227, septiembre-diciembre, pp. 1025-1040.

Hernández Soriano, Teresa y María de Jesús Teixidor de Otto, (1997) "La vieja fábrica de tabacos de Valencia" en Cuadernos de Geografía de la Universidad de Valencia. Núm. 61, pp. 77-96

Johnston Aguilar, René, (2005) La Antigua Guatemala: algunas secuelas tras el abandono de la ciudad debido al terremoto de 1773. Disponible en: https://www. academia.edu/352144/Algunas_secuelas_por_el_ abandono_de_La_Antigua_Guatemala_a_causa_del_ terremoto_de_1773 [consultado el 5 de agosto de 2013].

Laviana Cueto, María Luisa, (1985) "El estanco del tabaco en Guayaquil” en Temas Americanistas. Núm. 5, pp. 68105

Luján Muñoz, Jorge, (2000) "El establecimiento del Estanco del Tabaco en el Reino de Guatemala" conferencia dictada en el $V$ Congreso Centroamericano de Historia, Universidad de El Salvador, San Salvador, 18-21 de julio del 2000. Disponible en: www. hcentroamerica.fcs.ucr.ac.cr/Contenidos/hca/cong/ mesas/cong5/docs/lColll.pdf [consultado el 8 de febrero de 2013].

Moreno Coello, Georgina, (2012) "Alcaldes mayores y subdelegados frente a la siembra clandestina de tabaco: Papantla, 1765-1806" en América Latina en la Historia Económica. Año 19, núm. 3, septiembre-diciembre, pp. 26-234. Disponible en: www.scielo.org.mx/scielo. php?pid=S1405-22532012000300007\& \&cript $=$ sci arttext [consultado el 9 de febrero de 2013]. 
Ruiz Trapero, María, (2004) "La reforma monetaria de los reyes católicos: su importancia histórica" en Galende Díaz, Juan Carlos (dir.), III Jornadas Científicas sobre Documentación en época de los Reyes Católicos. Madrid, Departamento de Ciencias y Técnicas Historiográficas de la Universidad Complutense de Madrid. Disponible en: http://www.ucm.es/ data/cont/docs/446-2013-08-22-10\%20reforma.pdf [consultado el 17 de octubre de 2013].

Ruiz Trapero, María, (2007) "La reforma monetaria de Felipe V: su importancia histórica" en María del Mar Royo Martínez, Susana Cabezas Fontanilla y Manuel Salamanca López (eds.), VI Jornadas Científicas sobre Documentación Borbónica en España y América (1700-1868). Madrid, Departamento de Ciencias y Técnicas Historiográficas de la Universidad
Complutense de Madrid. Disponible en: http:// www.ucm.es/data/cont/docs/446-2013-08-22-13\%20 reforma.pdf [consultado el 17 de octubre de 2013].

Saguier, Eduardo R., (s.f.) Genealogía de la tragedia argentina. Tomo II. Derrumbe del orden imperial absolutista y crisis del estado colonial (Río de la Plata, siglo XVIII). Disponible en: www.er-saguier.org/obras/gta/Tomo-II/Seccion-F/ Cap-16/0-MIL-05.pdf [consultado el 8 de febrero de 2013].

Zubiri Marín, María Teresa, (1989) "Un producto americano y su repercusión en la economía venezolana del s. XVIII: el tabaco" en Boletín Americanista. Núm. 39-40, pp. 265-275. Disponible en: www. raco.cat/index.php/boletinamericanista/article/ viewFile/98564/146161 [consultado el 8 de febrero de 2013]. 
Mapa 1. Reino de Guatemala, 1770

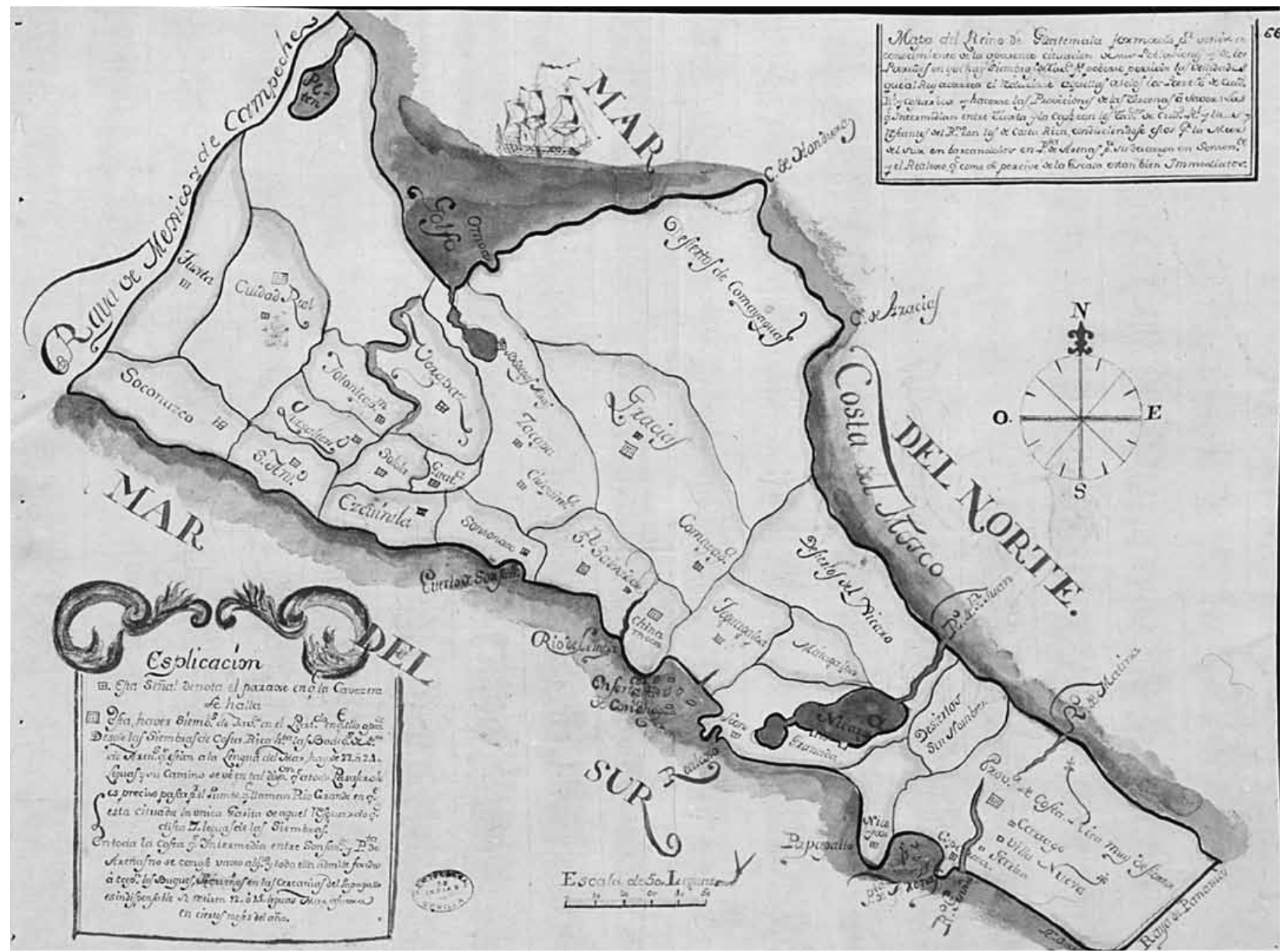

Fuente: Archivo General de Indias, MP-Guatemala 309. 